\title{
HUBUNGAN FUNGSI KEPEMIMPINAN KEPALA PUSKESMAS DENGAN MOTIVASI KERJA TENAGA KESEHATAN DI PUSKESMAS KEBUN LADA KECAMATAN BINJAI
}

\author{
Ikadawaty Hutabarat ${ }^{1}$, Masryna Siagian², Putranto Manalu ${ }^{3}$ \\ ${ }^{1}$ Universitas Prima Indonesia Jl Sekip Simp. Sikambing, Medan, Indonesia \\ 2Universitas Prima Indonesia \\ Email : ikadawatyhutabarat@gmail.com \\ DOI : https://doi.org/10.35451/jkg.v2i1.206
}

\begin{abstract}
Leadership has an influence on the work motivation of health workers in carrying out health services for the community. Based on an initial survey conducted at Kebun Lada Binjai Puskesmas there are still health workers who are lazy at work, often arrive late and go home early, often get together even though working hours are still inadequate, facilities and infrastructure are inadequate such as lack of seats so many patients who stand while waiting for health services, there are still health workers prioritize personal interests rather than the interests of the office in carrying out their duties. Based on the researcher's observations, it was found that the low work motivation of health workers in carrying out their duties and responsibilities. The purpose of this study was to determine the relationship of leadership functions (planning, supervision, and decision making) with the work motivation of health workers. This type of research is an analytic survey research, with cross sectional approach. The population in this study were all health workers as many as 47 people. The method of data analysis uses Chisquare test. The results showed that there was a very significant (strong) relationship between the relationship between planning and workforce motivation of health workers with a value of $p=0,000$ or $(p<0.05)$, the relationship of supervision with workforce motivation of workers with a value of $p=0,000$ or ( $p$ $<0.05)$, and the relationship between decision making and workforce motivation by health workers with a value of $p=0,000$ or $(p<0.05)$. Head of the Puskesmas must have the ability to lead subordinates well and be structured in order to carry out health programs well so as to provide work motivation with encouragement and the desire of health workers to carry out an activity or work well.
\end{abstract}

\section{Keywords: Leadership Function (Planning, Supervision and Decision Making), Work Motivation of Health Workers}

\section{Pendahuluan}

Pusat kesehatan masyarakat (puskesmas) merupakan tempat fasilitas pelayanan kesehatan yang menyelenggarakan upaya - upaya kesehatan masyarakat dan perseorangan tingkat pertama, dengan mengutamakan upaya promotif dan preventif, untuk mencapai derajat kesehatan masyarakat yang optimal di wilayah kerjanya (Depkes 2018).
Kepala Puskesmas adalah orang yang bertanggung jawab terhadap pembangunan kesehatan di tingkat kecamatan, Sedangkan Dokter Puskesmas adalah setiap tenaga kesehatan yang berkerja di Puskesmas yang diberi tugas, tanggung jawab, wewenang dan hak secara penuh oleh pejabat yang berwenang untuk memberikan pelayanan kesehatan kepada masyarakat pada sarana pelayanan kesehatan (Kemenkes $\mathrm{R}$ I 
2015). Fungsi kepemimpinan pada pokoknya adalah untuk menjalankan wewenang kepemimpinan. Keberhasilan seorang pemimpin dengan fungsi kepemimpinannya dapat dilihat dengan keberhasilan anggotanya (bawahannya) dalam melaksakan tugas dan tanggung jawab yang diberikan (Tilaar 2013).

Lima fungsi utama seorang pemimpin puskesmas, adalah untuk menjalankan prinsip manajemen puskesmas yaitu: a) Membuat perencanaan puskesmas b) Melakukan pengawasan terhadap tenaga kesehatan. c) Pengambilan keputusan untuk melakukan penilaian dan menjatuhkan pilihan alternatif (Makatumpias 2016).

Motivasi kerja tenaga kesehatan adalah sesuatu atau kondisi berpengaruh terhadap seseorang yang membangkitkan, menggerakkan, mendorong, dan mengarahkan untuk bertindak dan berperilaku secara tertentu sebagai upaya untuk memenuhi kebutuhan dan keinginan yang diharapkan, serta meningkatkan kebersamaan (Kamaluddin 2014; Nurbaeti 2014).

Motivasi kerja tenaga kesehatan merupakan daya penggerak yang meningkatkan semangat kerja seseorang dan mendorong orang tersebut untuk mengembangkan kreativitas serta mengarahkan semua kemampuan dan energi yang dimilikinya. (Tilaar 2013).

Ada hubungan Motivasi dengan kinerja pegawai (Terok 2015). Ada pengaruh kepemimpinan dengan motivasi kerja (Tilaar 2013).

Ada hubungan antara kepemimpinan dan motivasi kerja dengan kinerja tenaga kesehatan (Karuh 2016).

Berdasarkan survei pendahuluan yang dilakukan peneliti melalui wawancara langsung dengan 10 pasien, dimana bagian perencanaan yang dibuat oleh kepala puskesmas, pasien mengemukakan bahwa pada bagian sarana dan prasarana kurang memadai

\section{HASIL PENELITIAN}

seperti kurangnya tempat duduk sehingga banyaknya pasien yang berdiri sambil menunggu layanan kesehatan. Pada bagian pengawasan, pasien mengutarakan bahwa ketersediaan obat yang ada di farmasi hanya sedikit. Pada bagian pengambilan keputusan, pasien mengutarakan bahwa pegawai yang bekerja di puskesmas tersebut sering datang terlambat dan pulang lebih awal, beberapa pegawai sering berkumpulkumpul meskipun masih waktu jam kerja

Tujuan penelitian ini adalah untuk mengetahui hubungan fungsi kepemimpinan kepala puskesmas dengan motivasi kerja tenaga kesehatan di Puskesmas Kebun Lada Binjai tahun 2019.

\section{METODE PENELITIAN}

Jenis penelitian ini adalah penelitian survey yang bersifat analitik. Rancangan penelitian ini adalah dengan desain penelitian cross sectional (Notoatmodjo 2016; Sugiyono 2017). Survei analitik disini untuk menjelaskan hubungan fungsi kepemimpinan dengan motivasi kerja tenaga kesehatan pada Puskesmas Kebun Lada Binjai Medan Tahun 2019.

Populasi dalam penelitian ini adalah seluruh tenaga kesehatan di Puskesmas Kebun Lada Binjai Medan, yaitu 47 orang. Dalam penelitian ini, peneliti menggunakan teknik total populasi dimana semua populasi dijadikan sampel penelitian yaitu sebanyak 47 orang.

Penelitian ini dilakukan pada bulan Mei 2019 - Juni 2019. Pengumpulan data dalam penelitian dilakukan dengan wawancara dengan menggunakan alat bantu kuesioner. Uji Satistik pada analisis data menggunakan Uji Chi Square $\left(\mathrm{X}^{2}\right)$ dengan tingkat kepercayaan 95\% menggunakan program SPSS. 


\section{Analisis Univariat}

Tabel 1

Distribusi Frekuensi Hubungan Fungsi Kepemimpinan dengan Motivasi Kerja Tenaga Kesehatan pada Puskesmas Kebun Lada Binjai Medan Tahun 2019

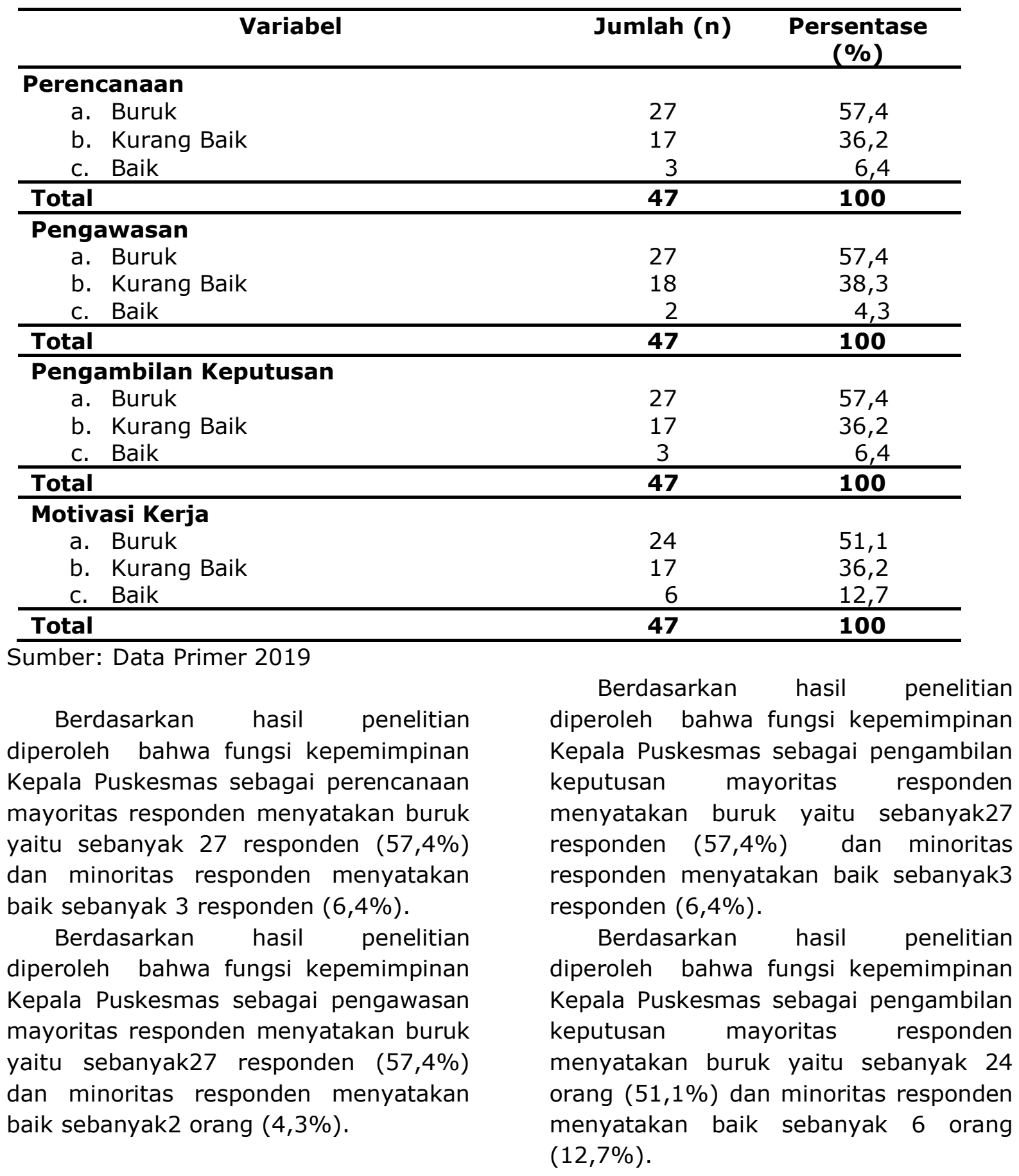




\section{Analisa Bivariat}

Tabel 2

Hubungan Perencanaan, Pengawasan dan Pengambilan Keputusan dengan motivasi kerja tenaga kesehatan pada Puskesmas Kebun Lada Binjai Medan Tahun 2019

\begin{tabular}{|c|c|c|c|c|c|c|c|c|c|}
\hline \multirow{3}{*}{ Variabel } & \multicolumn{6}{|c|}{ Motivasi Kerja Tenaga Kesehatan } & \multicolumn{2}{|c|}{ Total } & \multirow{3}{*}{$\begin{array}{c}P \\
\text { value }\end{array}$} \\
\hline & \multicolumn{2}{|c|}{ Buruk } & \multicolumn{2}{|c|}{$\begin{array}{c}\text { Kurang } \\
\text { Baik }\end{array}$} & \multicolumn{2}{|c|}{ Baik } & \multirow[t]{2}{*}{$\mathrm{N}$} & \multirow[t]{2}{*}{$\%$} & \\
\hline & $\mathrm{N}$ & $\%$ & $\mathrm{n}$ & $\%$ & $\mathrm{n}$ & $\%$ & & & \\
\hline \multicolumn{9}{|c|}{ Perencanaan } & \multirow{4}{*}{0,000} \\
\hline Buruk & 22 & 81,5 & 5 & 18,5 & 0 & 0 & 27 & 100 & \\
\hline Kurang Baik & 2 & 11,8 & 12 & 70,6 & 3 & 17,6 & 17 & 100 & \\
\hline Baik & 0 & 0 & 3 & 100 & 0 & 0 & 3 & 100 & \\
\hline \multicolumn{10}{|c|}{ Pengawasan } \\
\hline Buruk & 22 & 81,5 & 5 & 18,5 & 0 & 0 & 27 & 100 & \multirow{3}{*}{0,000} \\
\hline Kurang Baik & 2 & 11,1 & 12 & 66,7 & 4 & 22,2 & 18 & 100 & \\
\hline Baik & 0 & 0 & 0 & 0 & 2 & 100 & 2 & 100 & \\
\hline \multicolumn{10}{|c|}{$\begin{array}{l}\text { Pengambilan } \\
\text { Keputusan }\end{array}$} \\
\hline Buruk & 22 & 81,5 & 5 & 18,5 & 0 & 0 & 27 & 100 & \multirow{3}{*}{0,000} \\
\hline Kurang Baik & 2 & 11,8 & 12 & 70,6 & 3 & 17,6 & 17 & 100 & \\
\hline Baik & 0 & 0 & 0 & 0 & 3 & 100 & 3 & 100 & \\
\hline
\end{tabular}

Sumber: Data Primer 2019

Berdasarkan hasil penelitian diperoleh hasil uji chi square hubungan perencanaan dengan motivasi kerja tenaga kesehatan pada Puskesmas Kebun Lada Binjai Medan Tahun 2019dengan derajat kemaknaan $(a)=$ 0,05 dan diperoleh nilai $p$ value $=0,000$, maka Ho ditolak dan $\mathrm{Ha}$ diterima. Kesimpulannya ada hubungan yang sangat signifikan (kuat) antara hubungan perencanaan dengan motivasi kerja tenaga kesehatan pada Puskesmas Kebun Lada Binjai Medan Tahun 2019.

Berdasarkan hasil penelitian diperoleh hasil uji chi square hubungan pengawasan dengan motivasi kerja tenaga kesehatan pada Puskesmas Kebun Lada Binjai Medan Tahun 2019dengan derajat kemaknaan $(a)=$ 0,05 dan diperoleh nilai $p$ value $=0,000$, maka Ho ditolak dan $\mathrm{Ha}$ diterima. Kesimpulannya ada hubungan yang sangat signifikan (kuat) antara hubungan pengawasan dengan motivasi kerja tenaga kesehatan pada Puskesmas Kebun Lada Binjai Medan Tahun 2019.

Berdasarkan hasil penelitian diperoleh hasil uji chi square hubungan pengambilan keputusan dengan motivasi kerja tenaga kesehatan pada Puskesmas Kebun Lada Binjai Medan Tahun 2019dengan derajat kemaknaan $(a)=$ 0,05 dan diperoleh nilai $p$ value $=0,000$, maka Ho ditolak dan $\mathrm{Ha}$ diterima. Kesimpulannya ada hubungan yang sangat signifikan (kuat) antara hubungan pengambilan keputusan dengan motivasi kerja tenaga kesehatan pada Puskesmas Kebun Lada Binjai Medan Tahun 2019.

\section{PEMBahasan}

Hubungan perencanaan dengan motivasi kerja tenaga kesehatan 


\section{pada Puskesmas Kebun Lada Binjai Medan Tahun 2019.}

Berdasarkan hasil penelitian diperoleh bahwa ada hubungan perencanaan dengan motivasi kerja tenaga kesehatan pada Puskesmas Kebun Lada Binjai Medan Tahun 2019 dengan derajat kemaknaan $(a)=0,05$ dan di peroleh nilai $p$ value $=0,000$, maka $\mathrm{Ho}$ ditolak dan $\mathrm{Ha}$ diterima. Kesimpulannya ada hubungan yang sangatsignifikan (kuat) antara hubungan perencanaan dengan motivasi kerja tenaga kesehatan pada Puskesmas Kebun Lada Binjai Medan Tahun 2019.

Berdasarkan hasil penelitian Indar dkk (2013) dengan judul Kepemimpinan Kepala Puskesmas Dalam Penerapan Fungsi Manajemen di Puskesmas Lampa Kabupaten Pinrang. Dari 29 responden menunjukkan bahwa kepemimpinan kepala puskesmas sebagaiperencanaan bernilai baik sebanyak 26 responden $(89,7 \%)$. Pengorganisasian bernilai baik sebanyak 29 responden (100\%). Pelaksanaan bernilai baik sebanyak 28 pegawai $(96,6 \%)$. pengawasan bernilai baik sebanyak 25 pegawai $(86,2 \%)$. Sehingga berdasarkan uji Chi Square terdapat P value $=0,05$ (Indar 2013).

Berdasarkan hasil penelitian Alfarizi dkk (2014) dengan judul Hubungan Kepemimpinan Sebagai Motivator dengan Kinerja pegawai di PuskesmasBalung Jember. Berdasarkan Uji Statistik diperoleh hasil $p$ value $=0.007$. Nilai tersebut $<0.05$ sehingga $\mathrm{H} 1$ diterima yang berarti ada hubungan yang bermakna signifikan antara hubungan kepemimpinan sebagai motivator dengan kinerja pegawai dalam memberikan pelayanan kesehatan di puskesmas Balung Jember yang artinya, Kepemimpinan di Puskesmas Balung Jember masih belum melakukan perencanaan dan mengambil keputusan untuk menyelesaikan masalah yang ada karena Kepala puskesmas tidak melibatkan bawahan untuk memberikan solusi yang terbaik dengan cara-cara yang baru (Alfarizi 2014).

Menurut asumsi peneliti bahwa dari 47 responden ada 27 responden mengatakan fungsi kepemimpinan Kepala Puskesmas sebagai perencanaan bernilai buruk. Kepala Puskesmas jarang mempertimbangkan tujuan setiap kegiatan puskesmas, jarangmelakukan rencana usulan kegiatan yang melibatkan tenaga kesehatan, tidak melakukan pengajuan perencanaan kegiatan dan anggaran sesuai dengan realita kebutuhan dan mempertimbangkan kemudahan dan hambatan dalam pelaksanaan kegiatan. Karena perencanaan yang buruk mengakibatkan motivasi kerja tenaga kesehatan menurun sehingga dalam melakukan pelayanan kesehatan terhadap masyarakat menjadi tidak efektif karena tidak adanya tujuan perencanaan kegiatan yang disusun dengan baik. Oleh karena itu untuk meningkatkan motivasi kerja tenaga kesehatan maka kepala puskesmas dalam menjalankan fungsi perencanaan harus membuat perencanaan secara mendalam tentang rencana kegiatan yang akan dilakukan untuk meningkatkan kualitas pelayanan kesehatan di Puskesmas Kebun Lada Binjai.

Perencanaan merupakan suatu kegiatan atau proses penganalisaan dan pemahaman sistem, penyusunan konsep dan kegiatan yang akan dilaksanakan untuk mencapai tujuan-tujuan demi masadepan yang baik. Fungsi perencanaan memiliki hubungan yang sangat erat dengan pengambilan keputusan. Dalam pengambilan keputusan sangat diperlukan pada setiap hirarki proses perencanaan (Notoadmodjo, 2017).

\footnotetext{
Hubungan pengawasan dengan motivasi kerja tenaga kesehatan pada Puskesmas Kebun Lada Binjai Medan Tahun 2019.
} 
Berdasarkan hasil penelitian ini diperoleh bahwa ada hubungan pengawasan dengan motivasi kerja tenaga kesehatan pada Puskesmas Kebun Lada Binjai Medan Tahun 2019 dengan derajat kemaknaan $(a)=0,05$ dan di peroleh nilai $p$ value $=0,000$, maka Ho ditolak dan $\mathrm{Ha}$ diterima. Kesimpulannya ada hubungan yang sangat signifikan (kuat) antara hubungan pengawasan dengan motivasi kerja tenaga kesehatan pada Puskesmas Kebun Lada Binjai Medan Tahun 2019.

Berdasarkan hasil penelitian Said dkk(2016) dengan judul Hubungan Kepemimpinan, Pengawasan dan Motivasi dengan Peningkatan Disiplin Pegawai di Puskesmas Motaha Kabupaten Konawe Selatan. Hasil penelitian menunjukkan memiliki pengaruh dengan kedisiplinan pegawai di Puskesmas Motaha Kabupaten Konawe Selatan. berdasarkan uji Chi Square diperoleh kepemimpinan (X2 hitung $=6,562$, $\mathrm{R} \varnothing=0,436$ ), pengawasan (X2hitung = 4,147, $R \varnothing=0,357)$ danmotivasi (X2 hitung $=4,862, R \varnothing=0,382$ (Said 2016).

Berdasarkan hasil penelitian Basid (2017) dengan judul Pengaruh Pengawasan dan Komitmen Organisasi Terhadap Kinerja Pegawai Puskesmas Anjir Muara di Kabupaten Barito Kuala. Berdasarkan hasil $\mathrm{T}$ hitung $>\mathrm{T}$ Tabel (3.728 > 1.708.), terdapat pengaruh pengawasan terhadap kinerja pegawai di Puskesmas Anjir Muara Kabupaten Barito Kuala (Basid 2017).

Menurut asumsi peneliti bahwa dari 47 responden ada 27 responden mengatakan fungsi kepemimpinan Kepala Puskesmas sebagai pengawasan bernilai buruk. Kepala Puskesmas jarang mengadakan pengawasan langsung dalam setiap pekerjaan, jarang memberikan bimbingan dan saran kepada tenaga kesehatan dalam pelaksanaan tugas, dan tidak melakukan tindakan perbaikan atas kesalahan yang dilakukan saat pelaksanaan tugas. Pengawasan yang buruk mengakibatkan motivasi kerja tenaga kesehatan menurun sehingga tenaga kesehatan tidak optimal dalam melaksanakan pelayanan kesehatan sebagai tanggung jawabnya dan juga tidak mengikuti standar kerja yang ditetapkan, tidak bersedia bekerja sama dengan rekan kerja yang lain sehingga dalam hal meningkatkan derajat kesehatan masyarakat pun jauh dari harapan.

Kepala puskesmas harus melakukan pengawasan terhadap segala sesuatu pekerjaan yang dilakukan seorang tenaga kesehatan, untuk menciptakan keberhasilan kerja tenaga kesehatan. Pengawasan menjadi unsur penting dalam melakukan pembinaan individu, karena pengawasan merupakan tenaga penggerak bagi para tenaga kesehatan agar dapat bertindak sesuai dengan apa yang telah direncanakan menurut aturan yang berlaku. Pengawasan merupakan suatu hal yang sangat berperan dalam meningkatkan kinerja tenaga kesehatan sehingga dengan adanya pengawasan secara otomatis motivasi kerja tenaga kesehatan pun baik., karena motivasimenunjukkan minat individu terhadap pekerjaan, rasa puas, dan ikut bertanggung jawab terhadap aktivitas atau pekerjaan yang dilakukan. Jika motivasi kerja rendah, maka untuk kerja akan rendah juga meskipun memiliki kemampuan.

Kegiatan pengawasan pada dasarnya membandingkan kondisi yang ada dengan yang seharusnya terjadi. Dengan demikian dapat dikatakan bahwa kegiatan pengawasan memang diperlukan dalam rangka melihat apakah pekerjaan yang dilakukan sesuai dengan rencana yang dibuat atau tidak sehingga tujuan suatu organisasi dapat tercapai (Sulaiman 2011).

\section{Hubungan pengambilan keputusan dengan motivasi kerja tenaga kesehatan pada Puskesmas Kebun Lada Binjai Medan Tahun 2019.}

Berdasarkan hasil penelitian ini diperoleh bahwa ada hubungan 
pengambilan keputusan dengan motivasi kerja tenaga kesehatan pada Puskesmas Kebun Lada Binjai Medan Tahun 2019 dengan derajat kemaknaan $(a)=0,05$ dan diperoleh nilai $p$ value $=0,001$, maka Ho ditolak dan Ha diterima. Kesimpulannya ada hubungan yang sangatsignifikan (kuat) antara hubungan pengambilankeputusan dengan motivasi kerja tenaga kesehatan pada Puskesmas Kebun Lada Binjai Medan Tahun 2019.

Berdasarkan hasil penelitian Lumantow dkk (2017) dengan judul Hubungan Kepemimpinan dan Motivasi dengan Kinerja Tenaga Kesehatan di Puskesmas Kawangkoan. Hasil penelitian menunjukkan bahwa diperoleh nilai $p=$ 0,000 atau $(p<0,05)$ artinya, $\mathrm{H} 1$ diterima dan $\mathrm{HO}$ ditolak sehingga ada hubungan antara motivasi dengan kinerja tenaga kesehatan (Lamantow 2017).

Berdasarkan hasil penelitian Terok dkk (2015) dengan judul hubungan kepemimpinan dan motivasi dengan kinerja tenaga kesehata di Puskesmas Tuminting Kota Manado Desain penelitian ini kuantitatif dengan pendekatan cross sectional study. Populasi adalah seluruh pegawai Puskesmas Tuminting yang 40 responden. Pengumpulan data dilakukan dengan kuesioner. Penelitian ini menggunakan uji chi square (Terok 2015).

Hasil penelitian ini menunjukan dari 40 responden yang menilai kepemimpinan tidak baik sebanyak 7 responden $(17,5 \%)$ dan motivasi rendah sebanayak 10 responden $(25,0 \%)$ sementara kinerja tidak baik sebanyak 9 responden (22,5\%). Penelitian ini menunjukan terdapat hubungan antara kepemimpinan dengan kinerja tenaga kesehatan di Puskesmas Tuminting dengan nilai $p=0.001$ atau $(p<0.05)$ dan terdapat juga hubungan antara motivasi dengan kinerja tenaga kesehatan di Puskesmas Tuminting dengan $p=0.001$ atau $(p<0.05)$.

Hendaknya pemimpin harus lebih banyak bekerja sama dengan bawahannya dan melibatkan dalam pengambilan keputusan agar terciptanya kerjasama yang baik. Pengambilan keputusan merupakan proses yang digunakan untuk memilih suatu tindakan sebagai cara pemecahan masalah Dengan adanya kepemimpinan yang lebih baik dan motivasi yang lebih tinggi kepada bawahannya maka akan menghasilkan kinerja yang optimal dan baik di Puskesmas Tuminting Kota Manado.

Menurut asumsi peneliti bahwa dari 47 responden ada 27 responden mengatakan fungsi kepemimpinan Kepala Puskesmas sebagai pengambilan keputusan bernilai buruk. Kepala Puskesmas jarang dalam melakukan pengambilan keputusan dengan cepat dan tepat, jarang mempertimbangkan kemampuan masalah yang lalu dengan kemampuan tenaga kesehatan, pemimpin tidak kompeten dalam mengabil keputusan, jarang bersikap tegas kepada tenaga kesehatan yang tidak mematuhi peraturan. Karena pengambilan keputusan yang buruk mengakibatkan motivasi kerja tenaga kesehatan jadi rendah sehingga tenaga kesehatan tidak terarah dan tidak terkoordinasi dengan baik. Pengambilan keputusan hal terpenting dalam menentukan efektitifitas. setiap kegiatan baik menyangkut waktu, pelatihan, tujuan yang akan dicapai puskesmas. kepala puskesmas dalam periode apapun harus mengambil sebuah keputusan serta bertanggung jawab untuk mewujudkan visi dan misi puskesmas, serta kepala puskesmas harus menghitung kemungkinan keterbatasan sumber daya manusia serta kendala hubungan antara anggota serta peraturan yang berlaku dalam mewujudkan tujuan puskesmas.

Menurut Suhendra pengambilan keputusan merupakan serangkaian aktivitas yang dilakukan oleh seseorang dalam usaha memecahkan permasalahan yang sedang dihadapi 
kemudian menetapkan berbagai alternatif yang dianggap paling rasional dan sesuai dengan lingkungan organisasi (Suhendra 2008).

\section{KESIMPULAN DAN SARAN}

Faktor yang berhubungan fungsi kepemimpinan dengan motivasi kerja tenaga kesehatan pada Puskesmas Kebun Lada Binjai Medan Tahun 2019 adalah fungsi kepemimpinan sebagai perencanaan, pengawasan, dan pengambilan keputusan.

Perlu adanya perbaikan fungsi kepemimpinan agar meningkatkan motivasi kerja tenaga kesehatan sehingga tercapainya tujuan program program kesehatan yang ada di puskesmas.

\section{UCAPAN TERIMA KASIH}

Peneliti mengucapkan terima kasih kepada semua pihak yang telah banyak memberikan bantuan dan dukungan serta ucapan terima kasih kepada bapak / ibu kepala Dinas Kesehatan Kota Binjai dan UPT Puskemas Kebun Lada.

\section{DAFTAR PUSTAKA}

Alfarizi. 2014. "Hubungan Kepemimpinan Sebagai Motivator dengan Kinerja pegawai di Puskesmas Balung Jember." Universitas Sam Ratulangi.

Basid, Abd. 2017. "Pengaruh Pengawasan dan Komitmen Organisasi Terhadap Kinerja Pegawai Puskesmas Anjir Muara di Kabupaten Barito Kuala." Sekolah Tinggi Ilmu Kesehatan Cahaya Bangsa Banjarmasin.

Depkes. 2018. "Peraturan Menteri Kesehatan Republik Indonesia Nomor 75 Tahun 2014."

Indar. 2013. "kepemimpinan Kepala Puskesmas Dalam Penerapan Fungsi Manajemen Lampa Kabupaten Pinrang." Universitas Hasanuddin.

Kamaluddin. 2014. "Kepemimpinan, Motivasi Kerja Pegawai dan Kualitas Pelayanan." Universitas Riau.
Karuh, Anggraini. 2016. "Hubungan Antara Kepemimpinan dan Motivasi Kerja dengan Kinerja Kerja Pada Perawat Di RS. Byangkara Tingkat III." Universitas Sam Ratulangi.

Kemenkes R I. 2015. "Peraturan Menteri Kesehatan RI Nomor 75 Tahun 2014, Tentang Puskesmas." Jakarta.

Lamantow. 2017. "Hubungan Kepemimpinan dan Motivasi dengan Kinerja Tenaga Kesehatan di Puskesmas Kawangkoan."

Makatumpias. 2016. "Peran Kepala Puskesmas dalam Meningkatkan Kinerja Aparatur Sipil Negara."

Notoatmodjo, Soekidjo. 2016. Metodologi Penelitian Kesehatan. Jakarta: Rineka Cipta.

Nurbaeti. 2014. "Motivasi Kerja Tenaga Kesehatan di Puskesmas Walenrang Kabupaten Luwu."

Said, Dkk. 2016. "Hubungan Kepemimpina, Pengawasan dan Motivasi dengan Peningkatan Disiplin Pegawai Puskesmas Motaha, Kabupaten Konawe selatan."

Sugiyono. 2017. Metode Penelitian Kuantitatif, Kualitatif dan R\&D. Jakarta: Penerbit Alfabeta.

Suhendra, K. 2008. Keputusan Yang Tepat Kunci Sukses Pimpinan/ Manajer. Bandung: Mandar Maju.

Sulaiman, E. S. 2011. Manajemen Kesehatan. 2 ed. Yogyakarta: Gajah Mada University Press.

Terok, Dkk. 2015. "Hubungan Kepemimpinan dan Motivasi dengan Kinerja Tenaga Kesehatan di Puskesmas Tuminting Kota Manado."

Tilaar, dkk. 2013. "Pengaruh Tanggung Jawab dan Kepemimpinan dalam Motivasi Kerja Pegawai Puskesmas Modayag Barat." 